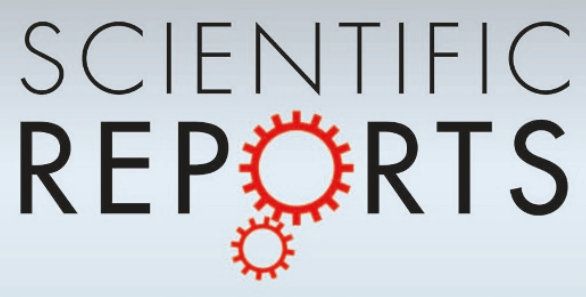

OPEN

SUBJECT AREAS:

SOLAR CELLS

NEAR-INFRARED SPECTROSCOPY

Received

16 June 2014

Accepted

20 October 2014

Published

7 November 2014

Correspondence and requests for materials should be addressed to Y.R. (yre@hunter.cuny. edu) or K.S. (kshum@ brooklyn.cuny.edu)

\section{Energy barrier at the N719-dye/CsSnl 3 interface for photogenerated holes in dye-sensitized solar cells}

\author{
Jin Zhang ${ }^{1,2}$, Chunhui Yu ${ }^{1,2}$, Lili Wang ${ }^{1,2}$, Yizhi Li ${ }^{1,2}$, Yuhang Ren ${ }^{1,3}$ \& Kai Shum ${ }^{1,4}$
}

\begin{abstract}
'Photovoltaic Research Center of Chinese Academy of Sciences, 1500 W Wenyi Rd, Hangzhou, Zhejiang $311121,{ }^{2}$ Sun Harmonics Ltd., 1500 West Wenyi Road, Hangzhou, Zhejiang 311121 , 3Physics Department, Hunter College of City University of New York, New York, NY 10065, ${ }^{4}$ Physics Department, Brooklyn College of City University of New York, Brooklyn, NY 11210.
\end{abstract}

This report is to address the question if black $\gamma$-polymorph of cesium tin tri-iodide ( $\mathrm{B}-\gamma$-CsSnI$\left.{ }_{3}\right)$ can be used as a solid-state hole-transport material in the conventional DSSCs with the N719 dye to replace the liquid electrolyte as reported by I. Chung et al. on Nature 485, 486, (2012). Here we demonstrate rigorously that B- $\gamma$-CsSnI ${ }_{3}$ is not energetically possible to collect photogenerated holes because of the large energy barrier at the interface of N719/B- $\gamma$-CsSnI ${ }_{3}$. Therefore, it cannot serve as a hole-transporter for the conventional DSSCs although it is a good hole-conducting material. A solution-based method was employed to synthesize the B- $\gamma$-CsSnI ${ }_{3}$ polycrystalline thin-films used for this work. These thin-films were then characterized by $\mathrm{X}$-ray diffraction, Hall measurements, optical reflection, and photoluminescence (PL). Particularly, spatially resolved PL intensity images were taken after B- $\gamma$-CsSnI ${ }_{3}$ was incorporated in the DSSC structure to insure the material integrity. The means of ultraviolet photoemission spectroscopy (UPS) was used to reveal why B- $\gamma-\mathrm{CsSnI}_{3}$ could not act as the substitute of liquid electrolyte in the conventional DSSCs. For the completeness, other two related compounds, one is the yellow polymorph of $\mathrm{CsSnI}_{3}$ and other is $\mathrm{Cs}_{2} \mathrm{SnI}_{6}$ with tetravalent tin instead of double-valent tin in $\mathrm{CsSnI}_{3}$ were also investigated by UPS.

$(2)$ ver the last a few years, a rapid progress has been made on the power conversion efficiency (PCE) of the Gratzel type of solar cells by making use of low-cost, solution-processable perovskite semiconductors ${ }^{1-8}$. It was recently reported to be $15.4 \%$ for the $\mathrm{CH}_{3} \mathrm{NH}_{3} \mathrm{PbI}_{3}$ based Gratzel solar cells ${ }^{8}$, widely expected to be improved further and possibly exceeding $20 \%$ in near future, hence challenging the mature crystalline-silicon based solar cell technology. Although the perovskite material itself is relatively inexpensive, the reported devices ${ }^{7,8}$ commonly use an expensive organic hole-transport polymer, called spiro-OMeTAD, which has a commercial price that is more than 10 times that of gold or platinum. Several attempts have been made to discover other holetransporters; most noticeable one was reported by In Chung et al. ${ }^{9}$ in which they claimed B- $\gamma$-CsSnI ${ }_{3}$ could be used as hole-transporting material in the conventional dye-sensitized DSSCs with the N719 dye. Their devices had an efficiency of $10.6 \%$ along with other improvements. $\mathrm{CsSnI}_{3}$ is a perovskite semiconductor ${ }^{10}$. If their claim could be rigorously verified, it would infer a great possibility of fabricating high performance perovskite based solar cells all by low-cost solution processes. Many research groups have been working hard to confirm their results; it apparently is fraught with many difficulties. In this communication, we demonstrate that $\mathrm{B}-\gamma$-CsSnI $\mathrm{I}_{3}$ is not possible to collect photogenerated holes energetically. Therefore, it cannot serve as a hole-transporter in the conventional DSSCs using the N719 dye as an absorption material, although it is generally a good hole-conducting material. With a motivation of verifying if $\mathrm{B}-\gamma-\mathrm{CsSnI}_{3}$ can be served as a hole-collector as well as a holetransporter, a reliable process is used to fabricate the conventional DSSCs with an obtainable PCE of 7.1\%. A low-cost and solution-based method is then employed to synthesize B- $\gamma$-CsSnI 3 thin-films. These thin-films are then characterized by X-ray diffraction (XRD), Hall measurements, and optical reflection, and PL spectroscopy before they are used to replace liquid electrolyte in DSSCs. Particularly, spatially resolved PL intensity images of photo-anode are used to insure the material integrity after $\mathrm{B}-\gamma-\mathrm{CsSnI}_{3}$ has been blended into the DSSC structure $\left(\mathrm{TiO}_{2} / \mathrm{N} 719 / \mathrm{B}-\gamma-\mathrm{CsSnI}_{3}\right)$. Ultraviolet photoemission spectroscopy (UPS) is used to manifest why B- $\gamma-\mathrm{CsSnI}_{3}$ cannot energetically collect the photogenerated holes generated in the N719 dye. To eliminate the possibility of B$\gamma$-CsSnI 3 being transformed into other compounds when it is blended into DSSCs, two related compounds, one is the yellow polymorph of $\mathrm{CsSnI}_{3}\left(\mathrm{Y}-\mathrm{CsSnI}_{3}\right)$ and other is $\mathrm{Cs}_{2} \mathrm{SnI}_{6}$ with tetravalent tin instead of double-valent tin as in $\mathrm{CsSnI}_{3}$, are also investigated by UPS. 


\section{Results}

XRD data of $\mathrm{B}-\gamma-\mathrm{CsSnI}_{3}, \mathrm{Y}-\mathrm{CsSnI}_{3}$, and $\mathrm{Cs}_{2} \mathrm{SnI}_{6}$. Figure 1 (a) shows the XRD patterns of $\mathrm{B}-\gamma-\mathrm{CsSnI} 3, \mathrm{Y}-\mathrm{CsSnI}_{3}$, and $\mathrm{Cs}_{2} \mathrm{SnI}_{6}$, from the top to bottom panel, respectively. It is shown that all of the characteristic XRD peaks match well to the theoretically generated positions and related strengths shown as straight lines for $\mathrm{B}-\gamma-\mathrm{CsSnI}_{3}, \mathrm{Y}-\mathrm{CsSnI}_{3}$, and $\mathrm{Cs}_{2} \mathrm{SnI}_{6}$. This match validates the simple solution method used to synthesize $\mathrm{B}-\gamma-\mathrm{CsSnI}_{3}$ and other relevant methods to produce yellow polymorph of $\mathrm{CsSnI}_{3}, \mathrm{Y}$ $\mathrm{CsSnI}_{3}$, and $\mathrm{Cs}_{2} \mathrm{SnI}_{6}$. It is generally known, however, that B- $\gamma$ $\mathrm{CsSnI}_{3}$ is not stable; when it is exposed to organic solvents; it undergoes a reconstructive phase transition to $\mathrm{Y}-\mathrm{CsSnI} \mathrm{S}_{3}$ at room

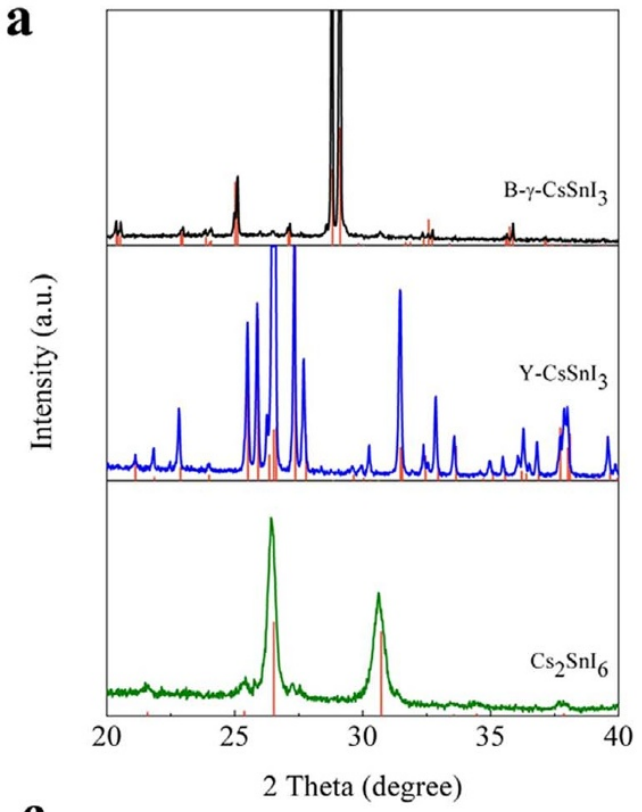

c

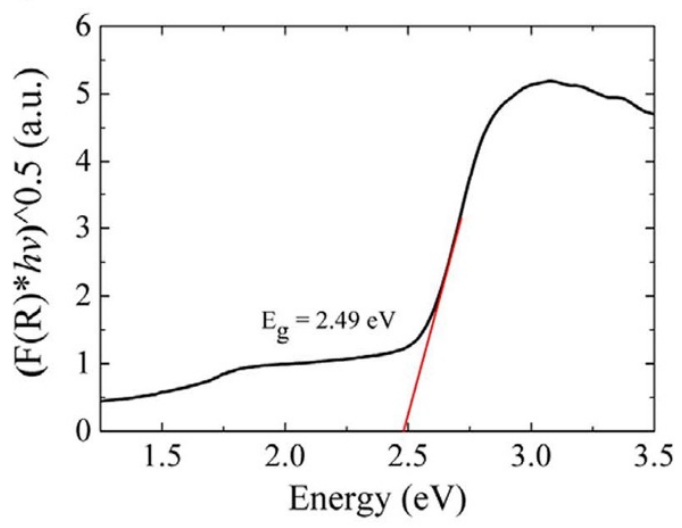

e

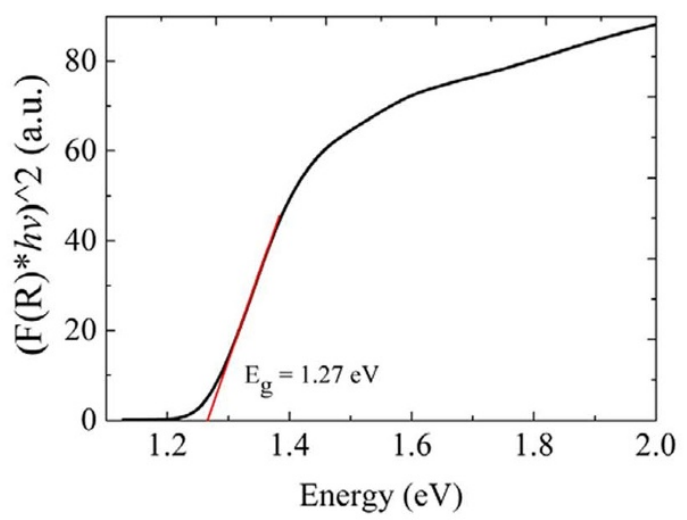

b
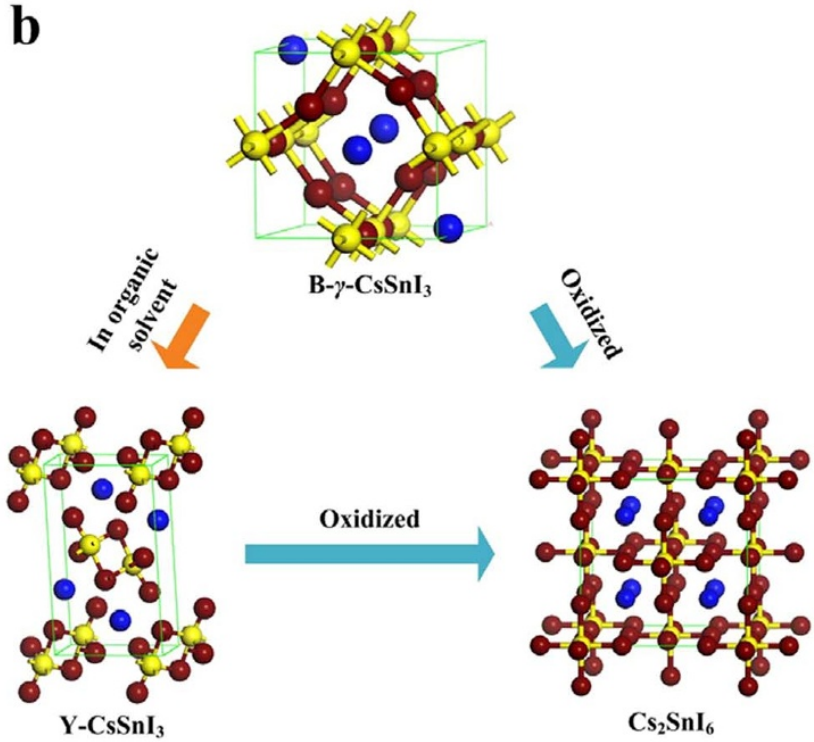

$\mathrm{Cs}_{2} \mathrm{SnI}_{6}$

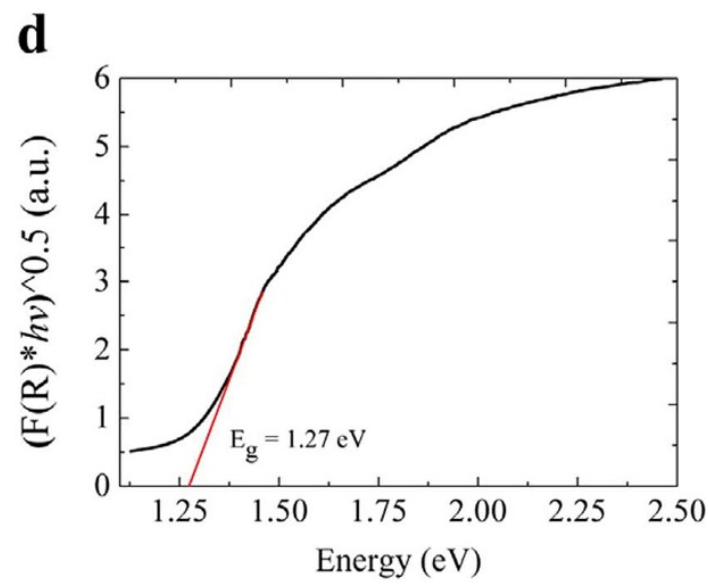

$\mathbf{f}$

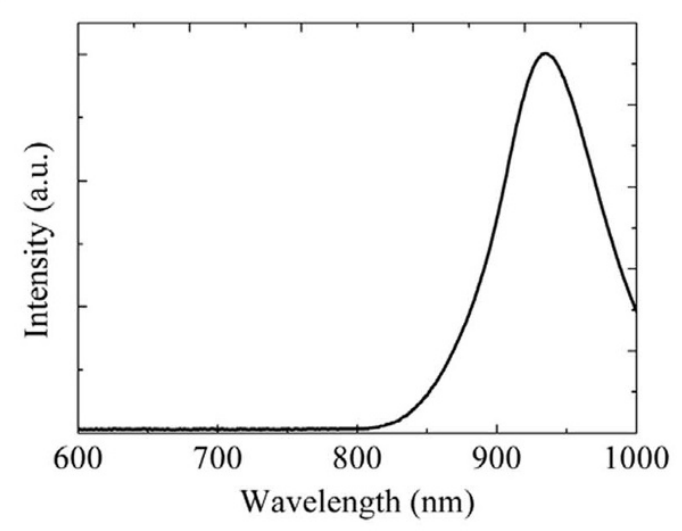

Figure $1 \mid$ Atomic Structures and optical properties of B- $\gamma-\mathrm{CsSnI}_{3}, \mathrm{Y}-\mathrm{CsSnI}_{3}$ and $\mathrm{Cs}_{2} \mathrm{SnI}_{6} \cdot$ (a) The XRD patterns of B- $\gamma-\mathrm{CsSnI}_{3}, \mathrm{Y}-\mathrm{CsSnI}_{3}$, and Cs $\mathrm{SnI}_{6}$. (b) Schematic representation of the phase changing processes from B- $\gamma$-CsSnI ${ }_{3}$ to Y-CsSnI ${ }_{3}$ and then to $\mathrm{Cs}_{2} \mathrm{SnI}_{6}$, red balls present "I", yellow balls present "Sn", and blue balls stand for "Cs". (c), (d) and (e) are UV-vis absorption spectra of Y- $\mathrm{CsSnI}_{3}, \mathrm{Cs}_{2} \mathrm{SnI}_{6}$, and B- $\gamma$-CsSnI 3 , respectively. $(\mathrm{F}(\mathrm{R}) * h v)^{\alpha}$ is proportional to absorption coefficient, where $\mathrm{F}(\mathrm{R})$ is the Kubelka-Munk function of reflection spectrum, $\mathrm{R}(v)$. The exponent, $\alpha$, is equal to 2 and 0.5 for direct and indirect band-gap semiconductor, respectively. (f) The PL spectrum of B- $\gamma$-CsSnI ${ }_{3}$ thin-film at room temperature. 
temperature. When $\mathrm{B}-\gamma-\mathrm{CsSnI} \mathrm{I}_{3}$ or $\mathrm{Y}-\mathrm{CsSnI}_{3}$ is being exposed to air, it will be oxidized in terms of tin atom and becomes $\mathrm{Cs}_{2} \mathrm{SnI}_{6}$. The atomic structures and relationship of the three related compounds are displayed in Figure 1 (b).

Optical properties of $\mathrm{B}-\gamma-\mathrm{CsSnI}_{3}, \mathrm{Y}-\mathrm{CsSnI}_{3}$, and $\mathrm{Cs}_{2} \mathrm{SnI}_{6}$. The optical properties of B- $\gamma-\mathrm{CsSnI}_{3}$ were initially reported by $\mathrm{K}$. Shum et al. ${ }^{10}$. It possesses a direct energy band-gap which was verified experimentally by the photoluminescence spectroscopy and theoretically by the first-principles calculations. The KubelkaMunk analysis of the measured reflection spectrum from the synthesized thin-film yields an optical band-gap of $1.27 \mathrm{eV}$ at room temperature, which is consistent with the reported value. Based on the first-principles simulations, $\mathrm{Y}-\mathrm{CsSnI}_{3}$ and $\mathrm{Cs}_{2} \mathrm{SnI}_{6}$ are indirect band gap semiconductors. Their band gaps are 2.49 and $1.27 \mathrm{eV}$, respectively using the Kubelka-Munk analysis as shown in Figure 1 (c), and (d), respectively.

Electrical properties of $\mathrm{B}-\gamma-\mathrm{CsSnI}_{3}, \mathrm{Y}-\mathrm{CsSnI}{ }_{3}$, and $\mathrm{Cs}_{2} \mathrm{SnI}_{6}$. In order to determine the unintentionally doped carrier density and type of $\mathrm{B}-\gamma-\mathrm{CsSnI}_{3}, \mathrm{Y}-\mathrm{CsSnI}{ }_{3}$, and $\mathrm{Cs}_{2} \mathrm{SnI}_{6}$ in their thin-film format synthesized by the solution method, a Hall sample holder with flat top was designed and fabricated, which contains Ti pads embedded in $\mathrm{SiO}_{2}$ on $\mathrm{Si}$ substrate. The Hall data for a batch of B- $\gamma$ $\mathrm{CsSnI}_{3}$ samples with three thicknesses are summarized in the Table 1 . The data consistently show that the $\mathrm{B}-\gamma-\mathrm{CsSnI}_{3}$ semiconductor thinfilm is of p-type with the carrier concentration of $\sim 10^{19} \mathrm{~cm}^{-3}$. The mobility of holes at room temperature increases from $\sim 3$ to $20 \mathrm{~cm}^{2} \mathrm{~V}^{-1} \mathrm{~s}^{-1}$ as the film thickness increases from 150 to $600 \mathrm{~nm}$. The unintentionally doped carrier density and type for $\mathrm{Y}_{-}-\mathrm{CsSnI}_{3}$ and $\mathrm{Cs}_{2} \mathrm{SnI}_{6}$ thin-films are not determined due to the limited sensitivity of our Hall measurement apparatus.

Uniformity and quality examination of $\mathrm{B}-\gamma-\mathrm{CsSnI} \mathrm{I}_{3}$ which has been infiltrated into photoanode. Since $\mathrm{B}-\gamma-\mathrm{CsSnI}_{3}$ is subject to the structural change and oxidation when it is being exposed to air, it is essential to check the uniformity and quality of $\mathrm{B}-\gamma-\mathrm{CsSnI}{ }_{3}$ when it has been infiltrated into the nano-crystal layer of photoanode. This is being done by the energy dispersive spectroscopy in which individual atomic element can be mapped and by the photoluminescence spectroscopy by which the polycrystalline quality of B- $\gamma-\mathrm{CsSnI}_{3}$ can be characterized. Figure 2 (a) shows the cross-sectional scanning electron microscopy (SEM) image of the photoanode, with a thickness of $\sim 27$ micrometers. The element of $\mathrm{Ti}, \mathrm{O}, \mathrm{Cs}, \mathrm{Sn}$, and I were mapped out as shown in Figure 2 (b), (c), (d), (e), and (f), respectively. These element maps indicate that all three elements contained in $\mathrm{B}-\gamma-\mathrm{CsSnI} \mathrm{I}_{3}$ are homogeneously permeated deep into the photoanode. In order to insure that the material infiltrated with the $\mathrm{TiO}_{2}$ nano-crystal network is indeed high quality polycrystalline $\mathrm{B}-\gamma-\mathrm{CsSnI}{ }_{3}$. A spatially resolved $\mathrm{PL}$ at the characteristic emission wavelength of $\mathrm{B}-\gamma-\mathrm{CsSnI}_{3}$ at $950 \mathrm{~nm}$ was measured from the back side of the photoanode as shown in Figure 2 (g). This two-dimensional PL intensity image demonstrates that the spin-coated $\mathrm{B}-\gamma-\mathrm{CsSnI}_{3}$ uniformly infiltrates into the nanoporous network of $\mathrm{TiO}_{2}$ layer and dose not turn to $\mathrm{Y}-\mathrm{CsSnI} \mathrm{I}_{3}$ or $\mathrm{Cs}_{2} \mathrm{SnI}_{6}$ during the material processing.

After the verification of uniformity and quality of $\mathrm{B}-\gamma-\mathrm{CsSnI}_{3}$, a complete batch of DSSC devices filtrated with B- $\gamma-\mathrm{CsSnI}_{3}$ were tested under the photoexcitation power density of $100 \mathrm{~mW}$ per $\mathrm{cm}^{2}$ (AM
1.5). The measured I-V curves for all the tested devices in several batches show straight lines and pass though the zero point of the I-V coordinate, indicating the devices lack of photovoltaic effects.

UPS spectra of $\mathrm{B}-\gamma-\mathrm{CsSnI}_{3}, \mathrm{Y}-\mathrm{CsSnI}_{3}$, and $\mathrm{Cs}_{2} \mathrm{SnI}_{6}$. In order to resolve the discrepancy between our experimental results and the published results by Chung et al. ${ }^{9,11}$, we rely on the UPS method to accurately determine the position of valence band maximum, $\mathrm{E}_{\mathrm{VB}}$, of $\mathrm{B}-\gamma-\mathrm{CsSnI}{ }_{3}$, which can directly reveal whether B- $\gamma-\mathrm{CsSnI}_{3}$ can collect the photogenerated holes in the N719 dye. It should be mentioned here that $\mathrm{B}-\gamma-\mathrm{CsSnI} \mathrm{I}_{3}$ was determined as a p-type semiconductor in the bulk format by Chung et al. ${ }^{9}$ and confirmed by our work as described in this work in the thin-film format. Therefore, there is no question about whether $\mathrm{B}-\gamma-\mathrm{CsSnI} \mathrm{I}_{3}$ is a good hole-conducting material or not. Figure 3 (a) shows the UPS spectrum of B- $\gamma-\mathrm{CsSnI}_{3}$, where the energy axis is calibrated with respect to the He-I photon energy of $21.21 \mathrm{eV}$. From this spectrum, the $\mathrm{E}_{\mathrm{VB}}$ of $\mathrm{B}-\gamma-\mathrm{CsSnI} \mathrm{I}_{3}$ is determined to be $-5.74 \mathrm{eV}$ below the vacuum level which is different from the value of $-4.92 \mathrm{eV}$ claimed by the previous report ${ }^{9}$. With the energy band-gap of $\mathrm{B}-\gamma-\mathrm{CsSnI} \mathrm{E}_{3}, \mathrm{E}_{\mathrm{g}}=1.27 \mathrm{eV}$ as determined by the $\mathrm{UV}$-vis reflection spectrum as shown in Figure 1 (e), the conduction band edge, $\mathrm{E}_{\mathrm{CB}}$, in reference to the vacuum level for $\mathrm{B}-\gamma-\mathrm{CsSnI}{ }_{3}$ is located at $-4.47 \mathrm{eV}$. In addition, the UPS spectra of $\mathrm{Y}_{-\mathrm{CsSnI}}$ and $\mathrm{Cs}_{2} \mathrm{SnI}_{6}$ have been taken and their values of $\mathrm{E}_{\mathrm{VB}}$ are indicated in Figure 3 (b) and (c), respectively.

Determination of the HOMO and LUMO energy levels of the N719 dye. Figure 4 (a) shows the measured UPS pattern of N719. The HOMO energy level (vs vacuum) of N719 is $-5.34 \mathrm{eV}$ and the band gap is $2.33 \mathrm{eV}$ as estimated from the UV-Visible absorption spectrum shown in Figure 4 (b). According to the values of HOMO and band gap, the LUMO energy level (vs vacuum) of N719 is $-3.01 \mathrm{eV}$. In addition, the HOMO level was also measured electrochemically via cyclic voltammetry (CV) with ferrocence/ ferrocenium $(\mathrm{Fc} / \mathrm{Fc}+)$ as the internal standard, by using the onset potential of the first oxidation peak. Figure 4 (c) illustrates the CV scans of N719 with dimethylformamide (DMF) as a solvent. The onset potential of oxidation for $\mathrm{N} 719$ was measured to be $0.66 \mathrm{~V}$ (vs $\mathrm{Ag} / \mathrm{AgCl}$ ), corresponding to $0.57 \mathrm{~V}$ (vs $\mathrm{Fc} / \mathrm{Fc}+$ ). The HOMO level for $\mathrm{N} 719$ was then estimated to be $-5.37 \mathrm{eV}$ (vs vacuum) on the basis of a stable oxidation potential of $-4.8 \mathrm{eV}$ (below vacuum level) for $\mathrm{Fc} / \mathrm{Fc}+$. This value is in agreement with the value determined by the UPS method.

\section{Discussion}

The UPS spectra of B- $\gamma-\mathrm{CsSnI}_{3}, \mathrm{Y}-\mathrm{CsSnI}_{3}$, and $\mathrm{Cs}_{2} \mathrm{SnI}_{6}$ were measured from three batches of fresh samples to enhance the accuracy of extracted values of $\mathrm{E}_{\mathrm{VB}}$. With the consideration of measurement variations, the $\mathrm{E}_{\mathrm{VB}}$ values for $\mathrm{B}-\gamma-\mathrm{CsSnI} 3, \mathrm{Y}-\mathrm{CsSnI}_{3}$, and $\mathrm{Cs}_{2} \mathrm{SnI}_{6}$ are $-5.74 \pm 0.12,-5.63 \pm 0.08$, and $-5.94 \pm 0.04 \mathrm{eV}$, respectively. To insure the consistency, the values of HOMO and LUMO for the N719 dye, were also measured by the UPS method to be -5.34 and $-3.01 \mathrm{eV}$, respectively. These values were also experimentally confirmed by the CV measurements. They are in agreement with the reported values in the literature ${ }^{12,13}$. Figure 5 shows the energy band alignments of the $\mathrm{TiO}_{2}, \mathrm{~N} 719, \mathrm{~B}-\gamma-\mathrm{CsSnI}_{3}, \mathrm{Y}-\mathrm{CsSnI}{ }_{3}$, and $\mathrm{Cs}_{2} \mathrm{SnI}_{6}$. Three conclusions can be drawn by inspecting this figure. First, there is a well-established energy barrier with a value of $0.40 \mathrm{eV}$ at the

Table 1 | Summary of the Hall data taken from a batch of B- $\gamma$-CsSnl 3 samples

\begin{tabular}{lccc} 
Thickness $(\mathrm{nm})$ & Mobility $\left(\mathrm{cm}^{2} \mathrm{~V}^{-1} \mathrm{~s}^{-1}\right)$ & Carrier Density $\left(10^{19} \mathrm{~cm}^{-3}\right)$ & Conduction Type \\
\hline 150 & $2.66 \pm 0.66$ & $4.10 \pm 0.27$ & $\mathrm{p}$ \\
300 & $4.78 \pm 0.59$ & $4.17 \pm 0.17$ & $\mathrm{P}$ \\
600 & $19.59 \pm 4.05$ & $3.05 \pm 0.53$ & $\mathrm{P}$
\end{tabular}



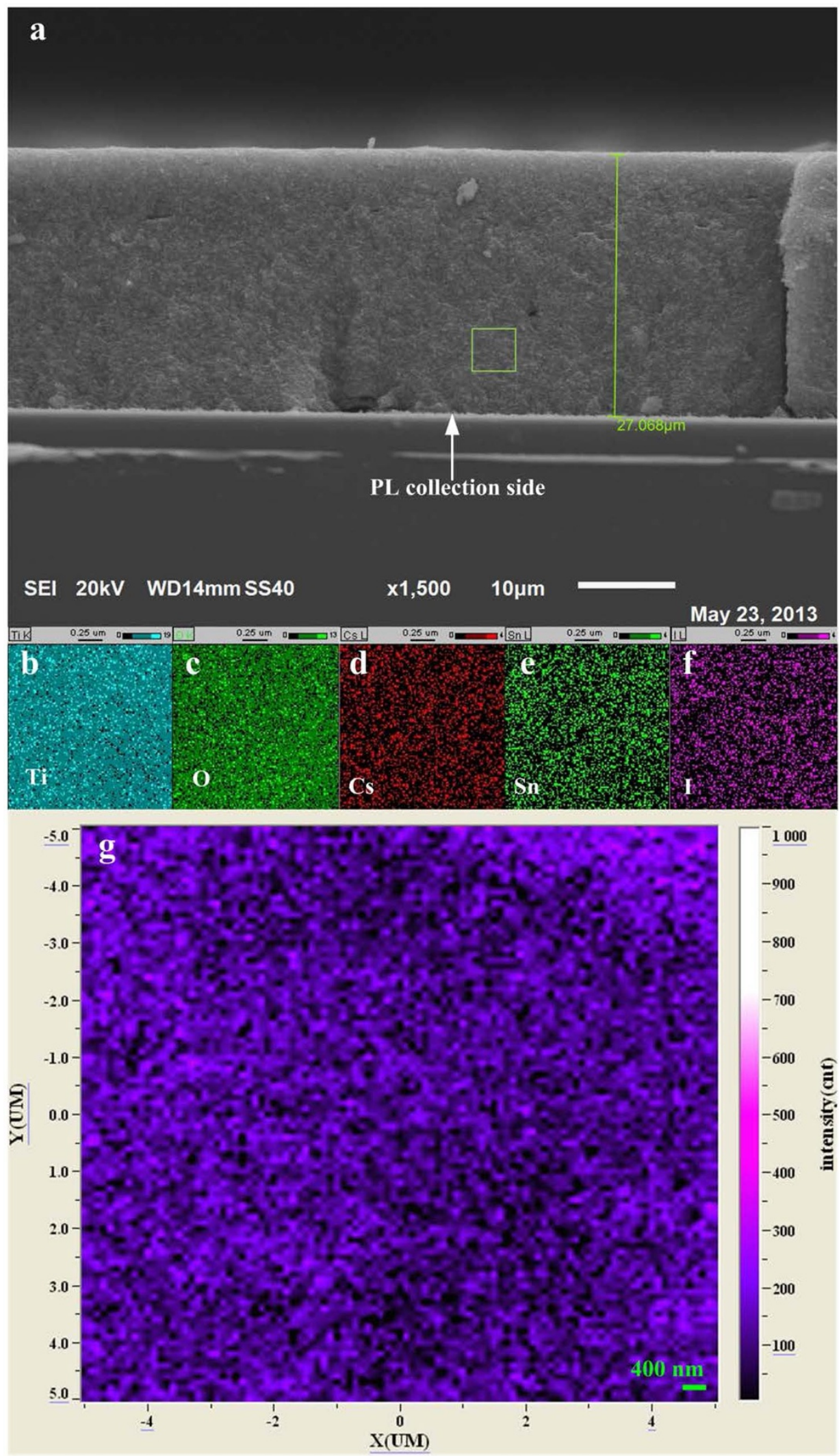

Figure $2 \mid$ Structural and material characterization of the B- $\gamma-\mathrm{CsSnI}_{3}$ coated photoanode (glass/TiO2/N719/B- $\gamma$-CsSnI 3 ). (a) Cross-sectional SEM image of the B- $\gamma$-CsSnI 3 coated photoanode. The material uniformity is shown by the elemental mapping images of (b), (c), (d), (e), and (f) for Ti, O, Cs, $\mathrm{Sn}$, and I atoms, respectively. (g) Spatially resolved PL centered at $950 \mathrm{~nm}$ emitted from B- $\gamma$-CsSnI ${ }_{3}$.

interface of N719-dye and $\mathrm{B}-\gamma-\mathrm{CsSnI}_{3}$. This value is much larger than the UPS experimental variations and can be considered to be reliable. With this large energy barrier, the photogenerated holes in the N719 dye cannot be collected into $\mathrm{B}-\gamma$-CsSnI 3 , revealing the reason why the photovoltaic effects were absent in the TiO2/N719/B- $\gamma$-CsSnI 3 structured DSSCs as described in the last section. Second, it is not possible 


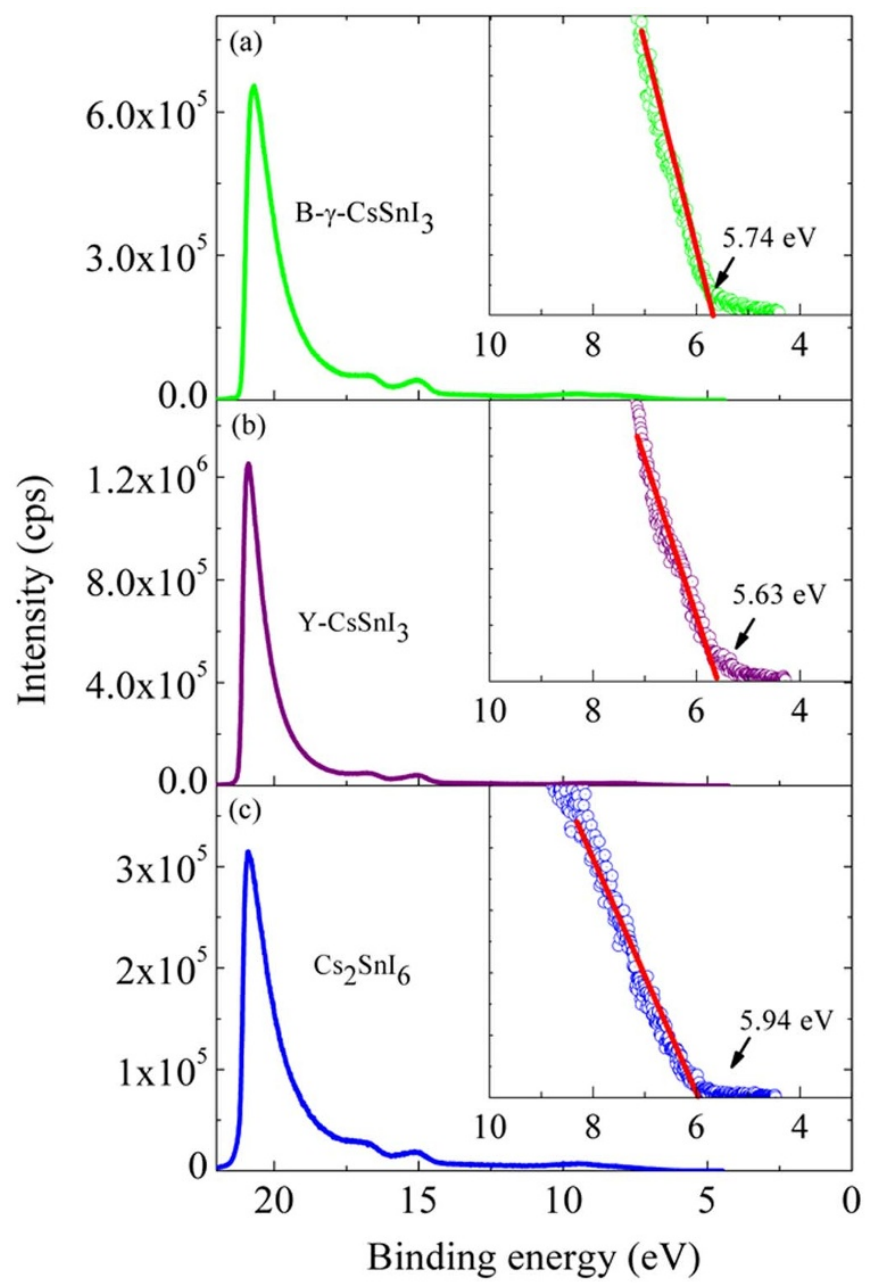

Figure 3 UPS spectra of $\mathrm{B}-\gamma-\mathrm{CsSnI}_{3}, \mathrm{Y}-\mathrm{CsSnI}_{3}$, and $\mathrm{Cs}_{2} \mathrm{SnI}_{6}$. As indicated in the insets, the value of $\mathrm{E}_{\mathrm{VB}}$ for $\mathrm{B}-\gamma-\mathrm{CsSnI}_{3} \mathrm{Y}-\mathrm{CsSnI}_{3}, \mathrm{Cs}_{2} \mathrm{SnI}_{6}$ are $-5.74,-5.63$, and $-5.94 \mathrm{eV}$ in reference to the vacuum level, respectively.

to consider B- $\gamma-\mathrm{CsSnI}_{3}$ in the reported DSSCs by Chung et al. ${ }^{9}$ might be transformed to $\mathrm{Y}-\mathrm{CsSnI}_{3}$ or $\mathrm{Cs}_{2} \mathrm{SnI}_{6}$ since the energy barriers at the interface of N719/Y-CsSnI 3 and N719/Cs $\mathrm{SnI}_{6}$ are $0.29,0.60 \mathrm{eV}$, respectively, as also illustrated in Figure 5. Third, the value of $\mathrm{HOMO}$ for most dyes are below $-5.5 \mathrm{eV}$, therefore, it is unlikely B- $\gamma-\mathrm{CsSnI}_{3}$ can be considered as a suitable candidate to replace the electrolyte in conventional DSSCs.

\section{Methods}

Method of synthesizing B- $\gamma-\mathrm{CsSnI}_{3}, \mathrm{Y}_{-} \mathrm{CsSnI}_{3}$, and $\mathrm{Cs}_{2} \mathrm{SnI}_{6}$. B- $\gamma-\mathrm{CsSnI}_{3}$ was prepared via a solution method. The CsI powders were first dissolved in $N, N$ dimethylformamide (DMF) to form a clear transparent solution. The milled $\mathrm{SnI}_{2}$ powders were added in to the CsI solution. The moral ratio of CsI and $\mathrm{SnI}_{2}$ was $1: 1$, and the concentration was $1 \mathrm{M}$. The mixed solution was stirred until forming a clear yellow solution which can be considered as the precursor solution of B- $\gamma$-CsSnI 3 . Finally, the precursor solution was spin-coated to a substrate and dried at $80^{\circ} \mathrm{C}, \mathrm{B}-\gamma-$ $\mathrm{CsSnI}_{3}$ with metallic luster was formed. Y-CsSnI ${ }_{3}$ was transformed from B- $\gamma$-CsSnI 3 in absolute ethanol. The B- $\gamma$-CsSnI 3 powders were put in absolute ethanol and stirred until becoming a bright yellow suspension. The suspension was then dried at $50^{\circ} \mathrm{C}$ to remove absolute ethanol and $\mathrm{Y}-\mathrm{CsSnI}_{3}$ poly-crystallites remained. All above process must be carried out under protection of $\mathrm{N}_{2}$ in a glove box with the water vapor and oxygen content under $1 \mathrm{ppm}$. To synthesize the $\mathrm{Cs}_{2} \mathrm{SnI}_{6}$ compound, B- $\gamma$-CsSnI $\mathrm{I}_{3}$ or $\mathrm{Y}-\mathrm{CsSnI}_{3}$ was placed in a drying oven in air; either of them would gradually turn to black $\mathrm{Cs}_{2} \mathrm{SnI}_{6}$

Method of fabricating the conventional DSSCs with PCE $>7 \%$ as a reference platform. $\mathrm{SnO}_{2}: \mathrm{F}$ (FTO) transparent conducting oxide coated glasses were used as the electrode for collecting electrons. A thin $\mathrm{TiO}_{2}$ blocking layer was fabricated by spin-coating $\mathrm{TiO}_{2}$ sol onto the FTO substrate, and then dried at $80^{\circ} \mathrm{C}$. The complex
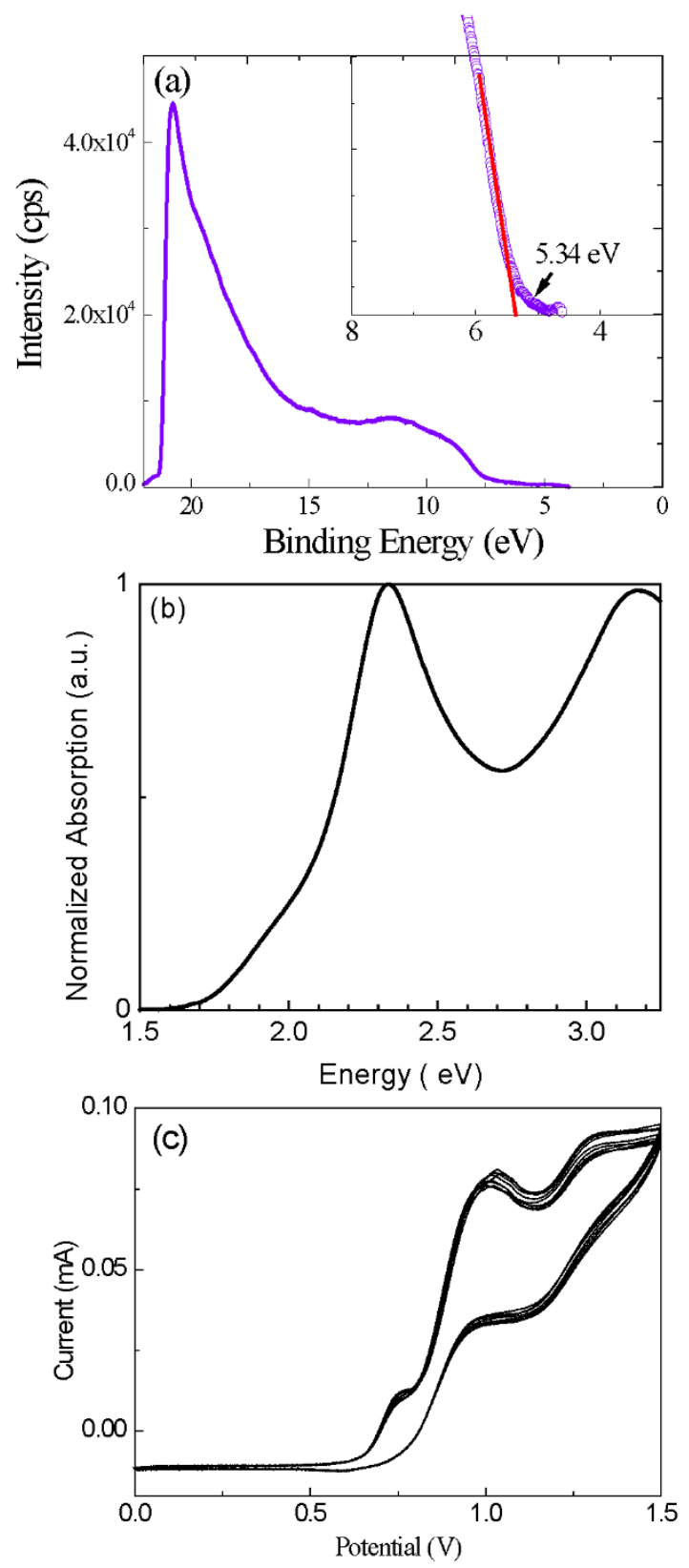

Figure $4 \mid$ Experimental determination of the HOMO and LUMO energy levels of the N719 dye. (a) UPS pattern of N719 indicating the HOMO energy level of $-5.34 \mathrm{eV}$ below the vacuum level, (b) Normalized UVvisible absorption spectrum of N719 in ethanol which provides an estimation of the band gap of N719, and (c) Cyclic voltammograms of the N719 dye in DMF measured at a scan rate of $50 \mathrm{mV} / \mathrm{s}$.

materials of the $\mathrm{TiO}_{2}$ sol consist of four components partitioned as follows ${ }^{14}$ : $\mathrm{Ti}\left[\left(\mathrm{CH}_{2}\right)_{3} \mathrm{CH}_{3}\right]_{4}: \mathrm{H}_{2} \mathrm{O}: \mathrm{HCl}: \mathrm{CH}_{3} \mathrm{CH}_{2} \mathrm{OH}=1: 4: 0.15: 50$. The $\mathrm{P} 25\left(\mathrm{TiO}_{2}\right)$ nano-particle paste was prepared as described in the literature ${ }^{15}$. The fabricated paste was screen printed onto the $\mathrm{TiO}_{2}$ blocking layer on the FTO substrate with an active area of $0.25 \mathrm{~cm}^{2}$, and then heat-treated at $200^{\circ} \mathrm{C}$ for $4 \mathrm{~h}$ before being calcined at $450^{\circ} \mathrm{C}$ for $4 \mathrm{~h}$ at a heating rate of $5^{\circ} \mathrm{C} / \mathrm{min}$. The sintered $\mathrm{TiO}_{2}$ mesoporous films deposited on FTO substrates were dyed by dipping in an absolute ethanol solution containing $0.5 \mathrm{mM}$ cis-diisothiocyanato-bis(2,29-bipyridyl-4,49-dicaboxylato) ruthenium(II) bis(tetrabutylammonium) (N719) for $24 \mathrm{~h}$ at room temperature, followed by rinsing with ethanol and drying. The PCE of the DSSCs fabricated using above-described procedures with a traditional liquid electrolyte is above $7 \%$.

Fabrication of the B- $\gamma-\mathrm{CsSnI}_{3}$ based solid-state DSSCs. Following the conventional DSSCs fabrication processes described in the last section up to the step of fabricating photoanode, then the $\mathrm{CsSnI}_{3}$ precursor solution was spin-coated in the dye adsorbed mesoporous $\mathrm{TiO}_{2}$ thin-film at $3000 \mathrm{r} / \mathrm{min}$ for $1 \mathrm{~min}$ and dried at $80^{\circ} \mathrm{C}$ for $30 \mathrm{~min}$ to 


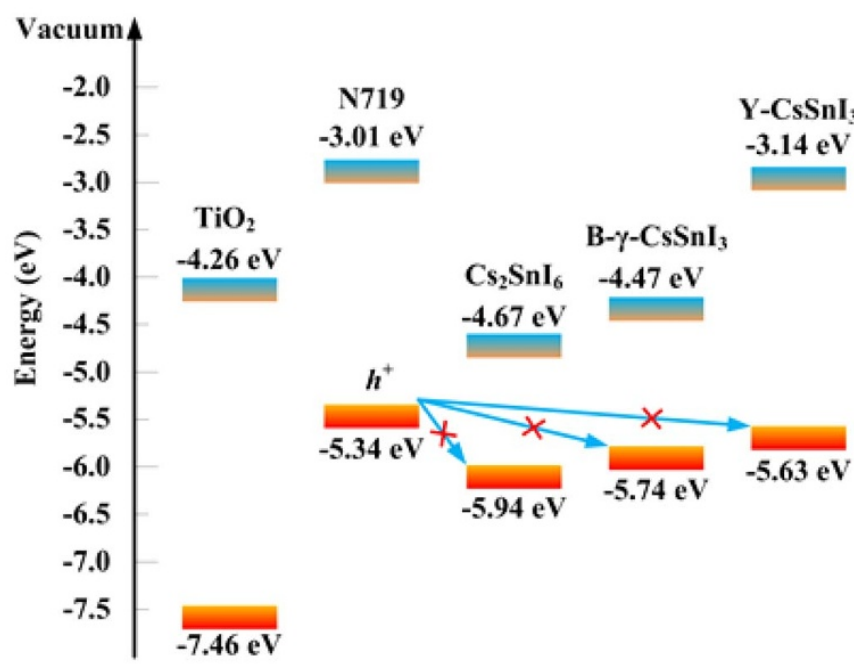

Figure $5 \mid$ Energy band alignments of the $\mathrm{TiO}_{2}, \mathrm{~N} 719, \mathrm{~B}-\gamma-\mathrm{CsSnI} \mathrm{I}_{3}, \mathrm{Y}-$ $\mathrm{CsSnI}_{3}$, and $\mathrm{Cs}_{2} \mathrm{SnI}_{6}$. The energy barrier between N719 and B- $\gamma-\mathrm{CsSnI}_{3}$ is $0.40 \mathrm{eV}$, the photogenerated holes in the N719 dye are energetically impossible to be collected by B- $\gamma-\mathrm{CsSnI}_{3}$ as indicated by a red cross.

form a network of B- $\gamma-\mathrm{CsSnI}_{3}$. (B- $\gamma-\mathrm{CsSnI}_{3}$ thin-films were also deposited by above spin-coating method.) The Pt counter electrodes were obtained by sputtering Pt onto the FTO substrates. The packaging processes of DSSCs described in Ref. 16 were used.

Description of other experimental apparatuses. The structural properties of B- $\gamma-$ $\mathrm{CsSnI}_{3}, \mathrm{Y}-\mathrm{CsSnI}{ }_{3}$, and $\mathrm{Cs}_{2} \mathrm{SnI}_{6}$ were characterized by using a PANalytical XRD spectrometer (Model EMPYREAN) with $\mathrm{Cu} \mathrm{K} \alpha$ radiation and operated at $40 \mathrm{kV}$ and $100 \mathrm{~mA}$ from 10 to $80^{\circ}$ in $2 \theta$, and the scanning speed was $10^{\circ} \mathrm{min}^{-1}$ at a step of $0.02^{\circ}$. The UV-Vis reflection spectra of $\mathrm{B}-\gamma-\mathrm{CsSnI} 3, \mathrm{Y}-\mathrm{CsSnI}_{3}$, and $\mathrm{Cs}_{2} \mathrm{SnI}_{6}$ were characterized by ISR-3100 integrating sphere in SHIMADZU UV-3600 UV-VIS-NIR spectrophotometer. The PL spectra were taken from a Nanolog system from Horiba Jobin Yvon using a laser at $532 \mathrm{~nm}$ as the excitation source. The Hall data were tested by a HL 5500 Hall system. The morphological property and EDS mapping of photoanode were observed by a Hitachi S-4800 (Hitachi, Japan) field-emission scanning electron microscopy (FE-SEM). The spatially resolved PL intensity image was taken by a LabRam HR 800 laser confocal Raman spectrometer (Horiba Jobin Yvon). The current-voltage curves of DSSCs were recorded by a Keithley 2400 sourcemeasure unit under the photoexcitation power density of $100 \mathrm{~mW} / \mathrm{cm}^{2}$ (AM 1.5) using the Newport Solar Simulator. UPS spectra were taken in an ultrahigh vacuum chamber of ESCALAB 250Xi Ver 2 electron energy spectrometer with a base pressure of $<2 \times 10^{-8} \mathrm{~Pa}$. The samples were cleaned by argon-ion sputtering $(2000 \mathrm{eV}$, $300 \mathrm{sec}$ ) to remove the surface contaminants. The excitation source for UPS measurements was He-I emission at $21.21 \mathrm{eV}$. The overall energy resolution is $\sim 0.02 \mathrm{eV}$. Cyclic voltammetry experiments were carried out by a windows-based electrochemical station (CHI660E) in a three-electrode cell configuration consisting of a platinum working electrode, a platinum counter electrode, and a $\mathrm{Ag} / \mathrm{AgCl}$ quasireference electrode with ferrocence/ferrocenium $(\mathrm{Fc} / \mathrm{Fc}+)$ as the internal standard using a scan rate of $50 \mathrm{mV} / \mathrm{s}$. The $\mathrm{N719}$ dye was dissolved in DMF with a concentration of $0.01 \mathrm{M}$. The supporting electrolyte was $0.1 \mathrm{M}$ tetrabutylammonium perchlorate $\left(\mathrm{C}_{16} \mathrm{H}_{36} \mathrm{NClO}_{4}\right)$. All of the characterization measurements were carried out at ambient temperature.

1. Jin, H. H. et al. Efficient inorganic-organic hybrid hetero-junction solar cells containing perovskite compound and polymeric hole conductors. Nature photon. 7, 486-491 (2013).
2. Jun, H. N. et al. Chemical management for colorful, efficient, and stable inorganic-organic hybrid nanostructured solar cells. Nano Lett. 13, 1764-1769 (2013).

3. Lee, M. M. et al. Efficient hybrid solar cells based on meso-superstructured organometal halide perovskites. Science 338, 643-647 (2012).

4. Ball, J. M. et al. Low-temperature processed meso-superstructured to thin-film perovskite solar cells. Energy Environ. Sci. 6, 1739-1743 (2013).

5. Burschka, J. et al. Sequential deposition as a route to high-performance perovskite-sensitized solar cells. Nature 499, 316-319 (2013).

6. Kim, H.-S. et al. High efficiency solid-state sensitized solar cell-based on submicrometer rutile $\mathrm{TiO}_{2}$ nanorod and $\mathrm{CH}_{3} \mathrm{NH}_{3} \mathrm{PbI}_{3}$ perovskite sensitizer. Nano Lett. 13, 2412-2417 (2013).

7. Kim, H.-S. et al. Lead iodide perovskite sensitized all-solid-state submicron thin film mesoscopic solar cell with efficiency exceeding 9\%. Sci. Rep. 2, 1-7 (2012).

8. Liu, M. et al. Efficient planar hetero-junction perovskite solar cells by vapor deposition. Nature 501, 395-398 (2013).

9. Chung, I. et al. All-solid-state dye-sensitized solar cells with high efficiency. Nature 485, 486-489 (2012).

10. Shum, K. et al. Synthesis and characterization of $\mathrm{CsSnI}_{3}$ thin films. Appl. Phys. Lett. 96, 221903 (2010)

11. Chung, I. et al. $\mathrm{CsSnI}_{3}$ : semiconductor or metal? High electrical conductivity and strong near-infrared photoluminescence from a single material: High holemobility and phase-transitions. J. Am. Chem. Soc. 134, 8579-8587 (2012).

12. Hwang, S. et al. A highly efficient organic sensitizer for dye-sensitized solar cells, Chem. Commun. 4887-4889 (2007).

13. Angelis, F. D. et al. Absorption spectra and excited state energy levels of the N719 Dye on $\mathrm{TiO}_{2}$ in dye-sensitized solar cell models, J. Phys. Chem. C 115, 8825-8831 (2011).

14. Que, W. et al. Thin film TiO2 electrodes derived by sol-gel process for photovoltaic applications. J. Power Sources 159, 353-356 (2006).

15. Ito, S. et al. Fabrication of screen-printing pastes from $\mathrm{TiO}_{2}$ powders for dyesensitized solar cells. Prog. Photovolt: Res. Appl. 15, 603-612 (2007).

16. Ito, S. et al. Fabrication of thin film dye sensitized solar cells with solar to electric power conversion efficiency over 10\%. Thin Solid Films 516, 4613-4619 (2008).

\section{Acknowledgments}

This work was partially supported by Chinese Academic Sciences through the Action Plan for Solar Energy program and by New York State Foundation for Science, Technology, and Innovation (NYSTAR) through the Center of Advanced Technology (CAT) at the City

University of New York. The work of K. S. was partially sponsored by Sun Harmonics.

\section{Author contributions}

J.Z., Y.R. and K.S. jointly conceived the idea of this study. J.Z. assisted in designing the experiments and in analyzing the experimental data. C.Y. prepared the $\mathrm{CsSnI}_{3}$ precursor solution. L.W. assembled DSSCs. Y.L. performed the characterization experiments. J.Z. prepared the initial manuscript and K.S. revised it. Y.R. and K.S. co-supervised and coordinated this work. All authors discussed the results and commented on the manuscript.

\section{Additional information}

Competing financial interests: The authors declare no competing financial interests.

How to cite this article: Zhang, J. et al. Energy barrier at the N719-dye/CsSnI ${ }_{3}$ interface for photogenerated holes in dye-sensitized solar cells. Sci. Rep. 4, 6954; DOI:10.1038/srep06954 (2014).

This work is licensed under a Creative Commons Attribution-NonCommercialNoDerivs 4.0 International License. The images or other third party material in this article are included in the article's Creative Commons license, unless indicated otherwise in the credit line; if the material is not included under the Creative Commons license, users will need to obtain permission from the license holder in order to reproduce the material. To view a copy of this license, visit http:// creativecommons.org/licenses/by-nc-nd/4.0/ 